\title{
A Comparative Study on the Cultivation Path of Key Competencies and STEAM Competencies
}

\author{
Rui Geng* \\ College of Literature, Bohai University, Jinzhou 121013, Liaoning Province, China \\ *Corresponding author: Rui Geng, gengrui@qymail.bhu.edu.cn
}

\begin{abstract}
The concept of STEAM education is essentially a multi-disciplinary and cross-disciplinary, integrated talent training model, based on the transformation of the world economic system and the response to the impact of education reform throughout the world. In recent years, schools in China have put forward educational theories for the integration and grafting of STEAM education based on the different cognition in Key Competencies and STEAM Competencies. This article first discusses the two initial concepts to identify cognitive bias; then, the curriculum design to explore the implementation of the two different strategies and the effect of the evaluation criteria described.
\end{abstract}

Keywords: Key Competencies; STEAM Competencies; Chinese curriculum; Students

Publication date: September 2021; Online publication: September 30, 2021

\section{Introduction}

In 2006, Georgette Yakman from Virginia Tech proposed the concept of STEAM education, adding "Art" to the original STEM model. Five elements which include science, technology, engineering, art, and mathematics are integrated in line with the initial pursuit of the 80's in the 20th century to advocate the talent model in cultivating innovative and comprehensive talents with the spirit of practice. The Organization for Economic Co-operation and Development (OECD) advocates the emergence of crossinternational cooperation and exchange of talents; that is, to train students' key competencies in order to ensure that they have those competencies in today's global development. In recent years, Key Competencies and STEAM Competencies (pays more attention to the process of cultivation than the idea of STEAM education) have become the topic of interest in current education. Increasing attention is on the cultivation of STEAM competencies, especially in Beijing and Shanghai, which are the forerunners of education reform. Therefore, the different ways to cultivate key competencies and STEAM competencies are worth thinking deeply.

\section{The cognitive bias of the original concept}

Whether it is the proposal of Key Competencies or STEAM Competencies, it enhances the competitiveness of talents in response to the development of international social market economy under the framework of the structuralist's teaching reform. In the face of such a complex international environment and technological development, what kind of talent does the national or multinational companies need. Researchers often point to STEAM education as the key competencies, but there is a conceptual value bias between the two.

The DeSeCo project has identified three basic key competencies that students should have at both the individual and societal levels, which include the ability to use tools interactively, to interact with heterogeneous social groups, and to act autonomously ${ }^{[1]}$. This means that all countries around the world 
are looking for versatile people who can handle emergencies. With the expectation of this standard, China has incorporated Key Competencies into the curriculum standards in the light of its own national conditions, requiring each discipline to embody its core literacy in the teaching process to enable students to look at problems through the integration of curriculum and cognitive thinking as well as to analyze the different characteristics and attributes of each discipline in the light of OECD data. With the standardization, it is possible to clearly recognize the talents that each discipline is trying to cultivate. In essence, the setting of the curriculum and textbook compilation of different disciplines constitute the cognition of the world from different units of disciplines; that is, to cognize and grasp the courses learned with disciplinary thinking, and the thought training is then applied in the related fields of life and social work.

STEAM Competencies, which integrates the definition of individual value goal in science, technology, engineering, art, and mathematics, has a programmatic control from students' initial psychological activities, learning scenes, and cognitive practice. In other words, it is the sum of the seven aspects of a student's psychological cognition ${ }^{[2]}$, including situational learning, practical inquiry, social interaction, rational decision-making, creative presentation, impact assessment, and it also provides scene reduction; that is, the emphasis on students' interactive experience in the course of learning and the enhancement of their ability to solve complex problems in interpersonal relationship and communication in order to ensure their comprehensive ability to deal with the information society, as well as to stimulate students' innovative thinking. Breaking the traditional teaching mode is a shock to the traditional liberal education mode.

If the core literacy educates students from point to person, then STEAM Competencies educates students face to face, breaks down the barriers of traditional knowledge disciplines, and tries to be more adaptable to the rapid development of the information age. Inevitably, the implementation process in different schools will neglect traditional disciplines. From the STEAM Competencies to the students and the related complex technical information to be processed, its training track should be on employmentoriented talents to adapt to the society after the completion of basic discipline training. Key Competencies starts from a point of view, where teachers are more targeted in classroom teaching. On the one hand, the collation and study of traditional knowledge should be emphasized; on the other hand, the subject's logical thinking and structural consciousness should be cultivated by gradually moistening things. This means that practitioners need to have a high level of knowledge. The basic knowledge of each discipline should be mastered, and at the same time, with a logical thinking about the uniqueness and logic consistency of different disciplines. The concept of STEAM Competencies to cultivate logic is more toward reflecting a fusion of vision, which makes the implementation of the two courses in the specific path of the ultimate design completely different.

\section{Different strategies in the implementation}

The STEAM curriculum reform is to enable students to break through the traditional modular learning of curriculum, which is one of the reasons why a comparative study of STEAM Competencies and Key Competencies is needed. The point is that there is a contradiction between the two curricula, which means that the goal of STEAM education cannot be generally directed toward the core of the subject. As an "imported product," the concept of STEAM education is an embodiment of seeking differences in the process of educational reform in China, and it deals with old problems with a new concept. However, the concept of STEAM education itself and the pursuit of STEAM Competencies are breaking down the original disciplinary barriers, not simply the knowledge instillation between disciplines, but the integration of disciplines. This means that students trained by STEAM are required to have some basic knowledge of the discipline to reconstruct a specific problem; thus, they need to have relevant knowledge, foster the premise of integrated thinking, and the theory carried out by the specific practice of life. In this way, teaching design requires teachers from different disciplines to open their minds to the problems in the 
curriculum design and change the traditional way of thinking in the compilation of teaching materials.

The curriculum design should begin from the problem, the knowledge of different subjects should be covered under a large unit, the whole curriculum should be guided by the problem thinking, and the choice of this kind of major theme should embody the complexity and intersection of subjects. As early as the 1960s, Schwab, the representative of the curriculum in structuralism, proposed the practical inquiry curriculum, which regards the teachers and the students as the main body of classroom research and development in order to balance the contradiction between information technology and education. It is a new model of curriculum development where through repeated situations to reach a consensus in a specific situation, the final decision-making action can be achieved; that is, the group deliberation ${ }^{[3]}$. However, this kind of collective deliberation is between different disciplines for curriculum understanding and curriculum evaluation. For example, in automobile production, from the construction of the automobile model to the analysis of the elements with physical chemistry, the calculation of the numbers, the application of the technology of human biology, the knowledge of the history and culture of the automobile, the monetary transaction policy among countries, the document propaganda of automobile sales, etc., this kind of problem setting breaks the modular learning of the traditional curriculum, realizes the intersection and integration of disciplines, carries on the scene design in the implementation of the specific curriculum, realizes the scene exploration, enables students to reach out to knowledge, technology, concepts, and scenarios of in-depth dialogue to form a real cross-disciplinary way of integrated thinking.

In practical teaching activities, the grasp and understanding of knowledge points should not be the only focus, but the subject thinking should also be formed from point to surface. The core literacy of Chinese is taken as an example, which includes the construction and application of language, the development and promotion of thinking, aesthetic appreciation and creation, as well as cultural inheritance and understanding. For the comprehensive arrangement of senior Chinese compulsory courses, optional compulsory courses, and elective courses, it is necessary for teachers to have a thinking mode that breaks through the limitations of the text and to grasp the structure of "big concept" and "big unit." This is quite different from traditional Chinese teaching, which requires constant refinement and explanation in terms of the pronunciation of words, the structure of Chinese grammar, the grasp of the thoughts and feelings of the articles, the historical and cultural details contained in the articles, as well as single knowledge difficulty which then increases in terms of the difficulty of the content materials, leading to the "exam-oriented education"-based ideological structure. However, the presentation of "big unit" and "big concept" is controlled by macro-thinking. In the course of curriculum implementation, it is to make clear the attributes of the Chinese subject and its position in order to better grasp the subject in trying to shape the direction of students' training. This shows that there are obvious differences between the training mode of STEAM Competencies and Key Competencies in the process of curriculum implementation. They also have different guidance for the formation of students' logical thinking, the practice of teaching activities, and the mode of training teachers.

\section{Curriculum with multi-attribute evaluation criteria}

The establishment of criteria is one of the important aspects to measure the implementation of the curriculum, whether it is STEAM Competencies or Key Competencies. At the beginning of the course, the goal is determined by the extension of the concept itself; that is, the emphasis on skills and problem-solving ability and even more on the educational process. One of the specific ways to promote curriculum reform is by paying attention to the consistency of the evaluation criteria and the cultivation of quality. Through the multi-evaluation criteria, there are different ways of testing in the learning process to examine whether students have other qualities and ability to improve. The cultivation of talents should not only adapt to the complex information environment, but also cultivate a sound personality and realization of self-value. The evaluation standard of this kind of demand should be carried out at the same time as the internal and external 
evaluation. For course evaluation, especially in China, testing should not be equated with evaluation, but should be used as a means of evaluation rather than as a final goal. In addition, traditional performance and teachers' evaluation should not be used as a single standard measurement.

The first is the traditional norm-referenced test, in which other students are taken as the yardstick to test the students' mastery of knowledge and ability under the same conditions. The test does not only involve knowledge inspection but also the analysis of the situation. Practical sciences should be measured more in terms of practical application rather than just written examination. Under the norm-referenced test method, the measurement of students' achievement is still a single evaluation system.

The second is the performance assessment of students. In the 1980s, the constructivist learning theory based on cognitive learning theory promoted the reform in the field of teaching and evaluation, where students are required to use their knowledge to solve a specific problem in a real or simulated situation in order to determine whether they have the ability to think independently and solve problems. The mastery of knowledge, the way the problems are solved, the ability of communication and cooperation, as well as critical thinking are all closely related to STEAM Competencies and Key Competencies. In addition, they are all focused on human development. The flexible setting of standards based on the examination content is to examine whether students have the ability to deal with a variety of complex problems and whether they have grown in comparison with their own development at different stages.

\section{Disclosure statement}

The author declares that there is no conflict of interest.

\section{References}

[1] Zheng J, 2021, Selection Principle, Technique and Characteristic of the Concept of OECD's Key Competencies - Analysis Based on the Qualitative Study of the DeSeCo. Studies In Foreign Education, 48(03): 21-33.

[2] Song S, Chen S, Shen G, 2021, The Definition, Significance and Representation of Student's STEAM Competency Curriculum. Teaching. Material and Method, 48(03): 21-33.

[3] Shi X, Xu LA, 2005, Review on the Curriculum Theory of Schwab. Teaching Material and Method, (01): 68-70. 